\title{
THE STOPPA PROCEDURE IN INGUINAL HERNIA REPAIR: TO DRAIN OR NOT TO DRAIN
}

\author{
Aldo Junqueira Rodrigues Jr., Jin Hwan Yoo, Edivaldo Massazo Utiyama and \\ Consuelo Junqueira Rodrigues
}

RODRIGUES Jr. AJ et al. - The Stoppa procedure in inguinal hernia repair: to drain or not to drain. Rev. Hosp. Clin. Fac.

Med. S. Paulo 58(2):97-102, 2003. repair.

OBJECTIVE: The objective of this study is to evaluate the benefits of drainage in the Stoppa procedure for inguinal

PATIENTS AND METHODS: The use of a suction drain was randomized at the end of the surgical intervention in 26 male patients undergoing inguinal hernia repair, divided into 2 groups: Group A, 12 patients undergoing drainage, and group B, 14 patients not undergoing drainage. On the second postoperative day, all patients underwent abdominal pelvic computed tomography scan examination to detect the presence of abdominal fluid collection.

RESULTS: In group A, no patient developed fluid collection in the preperitoneal space, and 1 patient presented with an abscess in the preperitoneal space on the 15 th postoperative day.

In group B, 12 patients presented with fluid collections in the preperitoneal space on computed tomography scan evaluation. However, only 3 patients presented minor complications. None of the patients developed a major complication.

CONCLUSION: The use of suction drainage with the Stoppa procedure does not provide any benefit.

DESCRIPTORS: Hernia. Inguinal Hernia. Prosthesis. Mesh. Drainage.

\section{INTRODUCTION}

The reconstruction of the posterior barrier of the groin represents one of the major objectives in groin hernia repair. There are 2 primary methods used to achieve this objective: "tissuerepair technique" and "tension-free repair". Recently, tension-free repair has become the gold standard procedure for repairing inguinal hernias. Many techniques have been described by different authors ${ }^{1-6}$. Tension-free repair involves the use of synthetic prosthetic materials for rebuilding the posterior inguinal wall. The prosthetic materials, now disposable, have a welltolerated bioreactivity, allow efficient fibroplasia, diminish postoperative pain, and significantly reduce the recurrence rate and convalescence period.

The Stoppa procedure, or giant prosthetic reinforcement of the visceral sac (GPRVS), is performed by wrapping the lower part of the parietal peritoneum with prosthetic mesh. The mesh contributes to a physiological healing process that creates a special bilateral anatomical reinforcement in the inguinal region, which effectively prevents inguinal hernia recurrence ${ }^{7-11}$. The proce-

From the General Surgery Division and Laboratory of Surgical Anatomy, Hospital das Clínicas, Faculty of Medicine, University of São Paulo.

Received for publication on August 08, 2002. dure's rationale is based on an elegant surgical and anatomical prosthetic placement that occludes the myopectineal ostium of Fruchaud. The GPRVS procedure requires wide dissection of the subfascial preperitoneal space. As a corollary, the GPRVS operation calls for the use of suction drainage. Sometimes this drainage procedure is responsible for longer hospitalization that may be as long as 9.7 days $^{11}$.

Since the description of GPRVS procedure, many surgeons have reported good outcomes; however, whether drainage is mandatory or how many suction drains should be placed in the preperitoneal space at the time of intervention is still controversial $^{8,9,12-19}$. The purpose of this study 
was to analyze the actual benefit of drainage in the GPRVS procedure and to answer the question of whether drainage is better than no drainage.

\section{PATIENTS AND METHODS}

\section{Patients}

Twenty-six male patients, of ASA I or II surgical risk, were prospectively randomized: Twelve patients presented with recurrent inguinal hernia, and 14 patients presented with bilateral groin hernia (Table 1).

All patients underwent general anesthesia, and each surgical intervention was performed by the same surgeon. None of the patients received heparin for prophylaxis of thromboembolism, since they were encouraged to walk on the first postoperative day (POD).

\section{Surgical technique}

The patient was positioned at the dorsal horizontal decubitus in a mild Trendelenburg position. A single dose of cephalothin was given intravenously immediately before the start of the operation. A midline infraumbilical incision was performed, and the preperitoneal space was opened. Dissection was performed in the retropubic space of Retzius in front of the bladder as far as the prostate. The dissection was extended laterally behind the rectus muscles and epigastric vessels in the retroinguinal space as far as the iliopsoas fascia. The sac of the inguinal hernia was identified; when the inguinal hernia was indirect, the sac and the spermatic cord were gently retracted, and the spermatic elements were carefully isolated. The preperitoneal cleavage plane was extended to expose the deep aspect of the obturator region below, the iliac vessels laterally, and the fascia of the psoas ma- jor muscle. The direct hernia sacs were inverted with a purse-string suture, and the indirect hernia sac was opened and a finger introduced within it to facilitate the isolation of the spermatic elements. In 8 patients the indirect hernia sac was resected, and in 16 patients the parietal peritoneum was inadvertently opened and its borders were approximated by continuous suture with polyglycolic acid 2-0 (Table 1). The contents of the spermatic cord were then parietalised. Careful hemostasis was carried out, and a chevron-shaped polypropylene mesh was placed and distended enough to guarantee the most flattened accommodation of the prosthesis in the preperitoneal space. The prosthesis was sutured at the pectineal ligament and the fascia of major psoas muscle with 2-0 polypropylene stitches to prevent dislocation. The dimensions of the mesh were measured in centimeters (Table 1).

\section{Randomization}

Once hemostasis in the preperitoneal space was obtained, the patient was randomly assigned to receive 1 of the 2 treatments: placement or not of a single $4.8 \mathrm{~mm}$ drain, which was carefully placed in the preperitoneal space

Table 1 - Characteristics of groups A and B.

\begin{tabular}{lccc}
\hline & $\begin{array}{c}\text { Group A } \\
\text { Without drainage } \\
(\mathrm{n}-=14)\end{array}$ & $\begin{array}{c}\text { Group B } \\
\text { With drainage } \\
(\mathrm{n}=12)\end{array}$ & $\begin{array}{c}\text { Total } \\
(\mathrm{n}=26)\end{array}$ \\
\hline Primary bilateral inguinal hernia (n) & 6 & 8 & 14 \\
Recurrent inguinal hernia (n) & 8 & 4 & 12 \\
Age (years) & 62.4 & 64.3 & 63.3 \\
& $(29-80)$ & $(45-77)$ & $(29-80)$ \\
BMI (kg/m $\left.{ }^{2}\right)$ & 22.9 & 23.1 & 23.0 \\
& $(19.5-24.8)$ & $(18.8-31.2)$ & $(18.8-31.2)$ \\
Mesh - width (cm) & 26.0 & 25.6 & 25.8 \\
& $(24-29)$ & $(24-28)$ & $(24-29)$ \\
Mesh - height (cm) & 16.8 & 16.7 & 16.7 \\
& $(13-19)$ & $(15-20)$ & $(13-20)$ \\
Peritoneal perforation (n) & 8 & 8 & 16 \\
Resection of the hernia sac (n) & 4 & 4 & 8 \\
Duration of surgery (min) & 105 & 113 & 108 \\
& $(70-135)$ & $(65-210)$ & $(65-210)$ \\
\hline
\end{tabular}

BMI: Body mass index. in front of the prosthesis and exteriorized at the right flank.

The 2 treatment groups in this trial were Group A, 14 patients without drainage, and Group B, 12 patients with suction drainage (Table 1).

\section{Postoperative evaluation}

On the second POD, all patients underwent an abdominal pelvic computated tomography (CT) scan to detect the presence of any fluid collection, with particular attention to the consistency and the volume in the preperitoneal space. All patients in Group A were discharged after the CT scan. In Group B, the criterion for taking out the suction drain was a 24hour drainage less than $50 \mathrm{~mL}$. When this volume was observed, the patient was discharged on the same POD.

All patients were instructed to return to the Division of Surgery if presenting with fever, incisional or inguinal pain, local ecchymosis, hematoma, or scrotal swelling.

The ambulatory followup was on the 15th POD, when a physical examination was performed to search for ecchymosis, seromas, hematomas, inflammation, or infectious signs at the infraumbilical or inguinal regions.

\footnotetext{
BMI: Body mass index.
} 


\section{RESULTS}

In Group A, 12 out 14 patients $(85.7 \%)$ presented with preperitoneal space fluid collection as revealed by CT scan on the second POD. From these 12 , only $3(21.4 \%)$ exhibited minor clinical manifestations: one showed a scrotal ecchymosis, the other an incisional hematoma, and the latter a seroma. All these complications were treated clinically with good outcomes. In this group the hospital stay ranged from 2 to 7 days (mean of 3.5 days).
No patient in the Group B presented with any fluid collection on the second POD revealed by CT scan. However, 1 patient had fever and pain in the infraumbilical region without any physical signs of inflammatory process on the 15th POD. This patient underwent an ultrasound scan of the lower abdomen with no findings of fluid collection. We performed an abdominal pelvic CT scan, which revealed fluid collection in the preperitoneal space (Fig. 1) that was absent in the CT scan performed on the second POD (Fig. 2). A guided needle

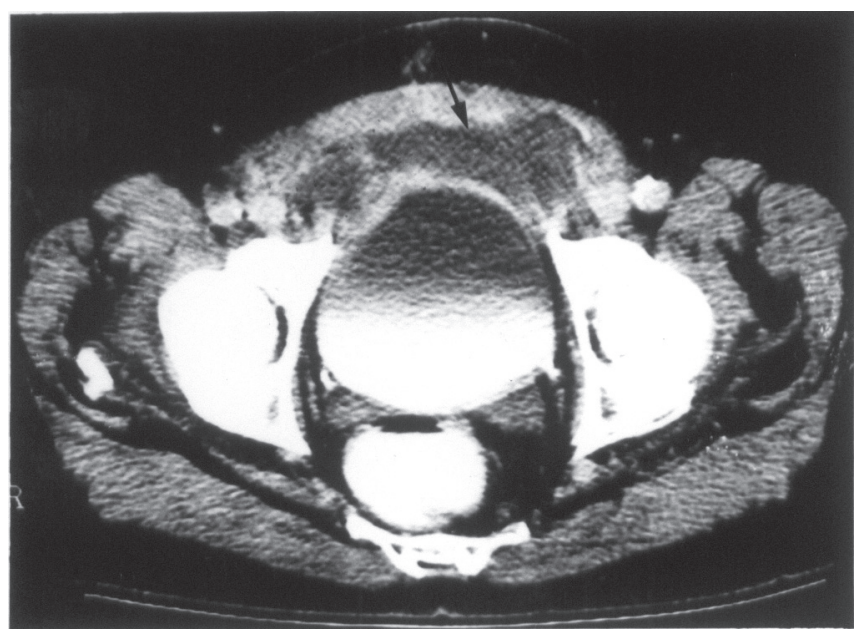

Figure 1 - Patient on the 15th POD. Abdominal pelvic CT scan showed an abscess in the preperitoneal space (arrow).

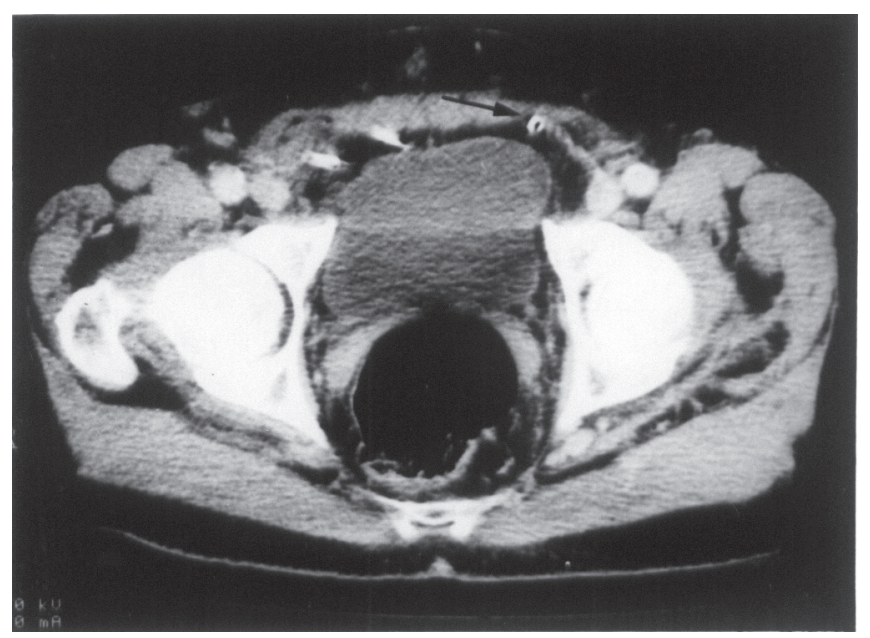

Figure 2 - Same patient on the second POD. Abdominal pelvic CT scan with no evidence of preperitoneal fluid collection. Arrow pointing to the suction drain.

puncture was performed, and about 60 $\mathrm{mL}$ of purulent secretion was aspirated; and a wire-guided tubular suction drainage was percutaneously inserted. Drainage was maintained for 4 days, and then the catheter was taken out. The patient recovered well, and no recurrence of inguinal hernia could be detected at the follow-up exam.

\section{DISCUSSION}

The Stoppa (GPRVS) procedure utilizes the many advantages of the preperitoneal approach in inguinal hernia repair. It has many advantages, particularly in cases of recurrent or multirecurrent inguinal hernias. We have used GPRVS for inguinal hernia repair since 1983. At present, this operation is performed in $22 \%$ to $28 \%$ of groin hernias referred to our General Surgery Division . A key feature of GPRVS is the application of Pascal's principle in mesh placement that reinforces the lower abdominal wall with an elegant anatomical approach that does not disturb groin structures, even in cases that were dissected before. However, the GPRVS procedure requires a very extensive dissection of the preperitoneal space for the insertion and wrapping of the visceral sac in a large bilateral mesh prosthesis.

Recent publications about the GPRVS have revealed that there still are authors who routinely use drainage with this procedure ${ }^{15,17}$; however, some others do not use drainage ${ }^{12,16}$, and some eventually use drainage ${ }^{13,20}$. When we looked for potential complications reported in these publications that might have arisen from fluid collections (seroma, hematoma, and infection), we found the following complication rate: 1) routine drainage: $3 \%{ }^{15}$ and $9 \%{ }^{17} ; 2$ ) use of suction drain according to intraoperative parameters: $10.2 \%^{20}$ and $24.6 \%{ }^{13}$; and 3) no drainage: $14 \%^{16}$ and $22.7 \%^{12}$. From these 
data, it appears that the use of a suction drain would bring some benefit. However, considering that Coda et al. ${ }^{13}$ reported a $24.6 \%$ rate of hematoma and seroma, even with the use of suction drainage in $83 \%$ of the patients in their study, it appeared that there was some controversy about the benefit of the drainage in GPRVS. To the best of our knowledge, this issue has not been studied before.

We have been using the procedure for repair of all inguinal hernias potentially disposed to recurrence, including those of obese patients with abdominal distension and patients with chronic bronchitis. However, for the present study, we included for prospective randomization 2 categories of patients with groin hernias: 1) recurrent or multirecurrent inguinal hernias, and 2) patients over 50 years with bilateral inguinal hernias. This protocol was aimed towards answering the question about the necessity of drainage in GPRVS, minimizing as much as possible patient comorbidities that could interfere with the interpretation of the outcome. It is clear that obesity interferes with the dissection. In this study, the patients had a body mass index (BMI) ranging from 18.81 to $31.20 \mathrm{~kg} /$ $\mathrm{m}^{2}\left(\right.$ mean $\left.=23.0 \mathrm{~kg} / \mathrm{m}^{2}\right)$. On the other hand, by considering the anthropometric parameters and the size of the prosthesis placed in preperitoneal space, we found that Groups A and B were homogeneous.

We performed the Stoppa procedure with special attention to the original description ${ }^{7-10}$. The choice of polypropylene mesh is a consequence of availability in our country. At the beginning of our experience, we used 4 drains in the preperitoneal space. Further we believed that 1 suction drain was sufficient by assuming that the preperitoneal space created by the surgical dissection represented only 1 bilateral continuous space; in fact, this strategy worked effectively.

Aspirative drainage in GPRVS was responsible for 2 to 7 days of postoperative hospital stay with a mean of 3.5 days, which is compatible to the findings of others ${ }^{11,14,16,20}$. Of the patients who did not undergo drainage, $85.7 \%$ presented with preperitoneal fluid collection revealed by CT scan on the second POD, but this was diagnosed clinically in only $21.4 \%$, with minimal clinical evidence that did not require any specific treatment. This finding suggests that it is safe to not drain systematically after the GPRVS procedure. This concept is strongly supported when we consider that the use of drainage did not prevent the collection of pus after the second POD in 1 patient. Moreover, the clinical signs of the inflammatory process are more reliable than the potential benefit that drainage in all patients might bring. The successful percutaneous puncture and drainage of fluid collection in 1 patient demonstrated that the presence of postoperative infectious fluid collection following GPRVS does not require that the mesh be taken off.

Thus, the results presented from Group A on clinical evaluation are similar to those reported by Solorzano et al. ${ }^{16}$ and Beets et al. ${ }^{12}$ who also did not use drainage systematically in GPRVS. Solorzano et al. ${ }^{16}$ reported $14 \%$ hematoma and infectious complications while Beets et al. ${ }^{12}$ reported $22.6 \%$ seroma, hydrocele, hematoma, and infectious complications.

Our results justify the concept that the GPRVS procedure is not an operation that routinely requires drainage. We are convinced that, for general use, precise case selection, and careful attention to anatomical and surgical principles are the foundations for every surgical procedure, including GPRVS.

We can safely propose that the use of aspirative drainage in GPRVS must be used in situations without good hemostasis. Schimitz et al. ${ }^{21}$ reported that in Bassini-Lotheissen inguinal hernia repair, patients receiving lowdose subcutaneous heparin have a high rate of hemorrhagic complications, with $22 \%$ hematomas and $13.3 \%$ ecchymosis. Similar results were also reported by Mumme et al..$^{22}$, including increased postoperative hematomas and subsequent increased surgical reintervention with anticoagulation in inguinal hernia surgery.

Finally, our results corroborate the unquestionable value of the GPRVS procedure as an efficient inguinal hernia repair technique that reduces the recurrence rate. The GPRVS procedure is not only the last weapon of defense, but is actually a good weapon. By assuming this posture, we think that we are safely decreasing postoperative stay, and as a consequence, improving the cost effectiveness of the procedure.

\section{RESUMO}

RODRIGUES Jr. AJ e col. Hernioplastia inguinal segundo procedimento de Stoppa: drenar ou não drenar. Rev. Hosp. Clin. Fac. Med. S. Paulo 58(2):97-102, 2003.
OBJETIVO: O objetivo do presente estudo é avaliar os benefícios da drenagem no procedimento de Stoppa no tratamento da hérnia inguinal.

PACIENTES E MÉTODOS: O uso da drenagem de aspiração contínua foi randomizado ao final do procedimento cirúrgico em 26 pacientes submetidos à correção da hérnia inguinal e divididos em dois grupos: 
Grupo A, com 12 pacientes submetidos à drenagem e Grupo $\mathrm{B}$, com 14 pacientes não submetidos à drenagem. No segundo dia de pós-operatório, todos os pacientes foram submetidos à tomografia computadorizada de abdome para a verificação de coleções abdominais.

RESULTADOS: No Grupo A, ne- nhum paciente apresentou coleção no espaço pré-peritonial. Por outro lado, um paciente desenvolveu abcesso no espaço pré-peritonial no décimo quinto dia de pós-operatório. No Grupo B, 12 pacientes apresentaram coleção préperitonial à tomografia. Entretanto, somente três apresentaram complicações menores. Nenhum paciente apresentou complicação maior.

CONCLUSÃO: O uso de drenagem de aspiração contínua no procedimento de Stoppa não traz nenhum benefício.

DESCRITORES: Hérnia. Hérnia Inguinal. Prótese. Tela. Drenagem.

\section{REFERENCES}

1. GILBERT AI - Sutureless repair of inguinal hernia. Am J Surg 1992; 163:331-335.

2. GILBERT AI, GRAHAM MF, VOIGT WJ - A bilayer patch device for inguinal hernia repair. Hernia 1999; 3:161-166.

3. LICHTENSTEIN IL, SHULMAN AG - Ambulatory outpatient hernia surgery. Including a new concept, introducing tensionfree repair. Int Surg 1986; 71:1-4.

4. LiCHTENSTEIN IL, SHULMAN AG, AMID PK et al. - The tension-free hernioplasty. Am J Surg 1989;157:188-193.

5. RUTKOW IM, ROBBINS AW - Mesh plug hernia repair: A followup report. Surgery 1995; 117:597-598.

6. TRABUCCO EE, TRABUCCO AF.- Flat plug and mesh hernioplasty in the "inguinal box": description of the surgical technique. Hernia 1998; 2:133-138.

7. STOPPA R - Prosthetic repair via the open abdomen. In: CHEVREL JP - Hernias and surgery of the abdominal wall. Berlin, Springer, 1998. p. 216-223.
8. STOPPA R, ABOURACHID H, DUClAYE C et al.- Plastie des hernies de l'aine. L'interposition sans fixation de tulle de Dacron par voie médiane sous-péritonéale. Nouv Presse Pr Med 1973;2:1949-1951.

9. STOPPA R, PETIT J, HENRY X - Unsutured Dacron prosthesis in groin hernias. Int Surg 1975;60:411-412.

10. STOPPA R, WARLAMOUNT CR - The pre-peritoneal approach and prosthetic repair of groin hernia. In: NYHUS LN, CONDON R - Hernia. $3^{\text {rd }}$ ed. Philadelphia, Lippincott, 1989. p. 199-255.

11. STOPPA R, WARLAUMONT CR, VERHAEGHE PJ et al. Prosthetic repair in the treatment of groin hernias. Int Surg 1986; 71:154-158.

12. BEETS GL, VAN GELDERE D, BAETEN CGMI et al. - Longterm results of giant prosthetic reinforcement of the visceral sac for complex recurrent inguinal hernia. Br J Surg 1996; 83:203-206.

13. CODA A, FERri F, MATTIO R et al. - L'intervento di Stoppa. Minerva Chir 1997; 52:565-569. 
14. MALAZGIRT Z, OZKAN K, DERVISOGLU A et al. - Comparison of Stoppa and Lichtenstein techniques in the repair of bilateral inguinal hernias. Hernia 2000; 4:264-267.

15. PRICOLO R, PARZIALE A, RIZZITELLI E et al. - La riparazione delle ernie inguinali e/o crurali com protesi gigante in mersilene in posizione preperitoneale. Minerva Chir 1993; 48:10071010.

16. SOLORZANO CC, MINTER RM, CHILDERS TC et al. Prospective evaluation of the giant prosthetic reinforcement of the visceral sac for recurrent and complex bilateral inguinal hernias. Am J Surg 1999; 177:19-22.

17. THAPAR V, RAO P, PRABHU R et al. - Giant prosthesis for reinforcement of visceral sac for complex bilateral and recurrent inguinal hernias: A prospective evaluation. J Postgrad Med 2000; 46:80-82.
18. VAN DAMME JPJ - A preperitoneal approach in the prosthetic repair of inguinal hernia. Int Surg 1985; 70:223-226.

19. WANTZ GE - Giant prosthetic reinforcement of the visceral sac. Surg Gynecol Obstet 1989; 169:408-417.

20. CHAMPAULT GG, RIZK N, CATHELINE JM et al. - Inguinal hernia repair. Totally preperitoneal laparoscopic approach versus Stoppa operation: Randomized trial of 100 cases. Surg Laparosc Endosc 1997; 7:445-450.

21. SCHMITZ R, KANSY M, MOSER KH et al. - Effect of low-dose subcutaneous heparin on postoperative wound hematomas: Randomized clinical trial on hospitalized inguinal hernia patients in Germany. World J Surg 1995; 19:416-419.

22. MUMME T, PEIPER CH, LORENZ $\mathrm{N}$ et al. - Does anticoagulation increase the risk of wound hematoma in inguinal hernia surgery? Hernia 2000; 4:275-281. 